\title{
Strumal Carcinoid of the Ovary: A Report of Two Cases
}

\author{
Xue Lin $\left.{ }^{(}\right)$, Neelam K. Shah ${ }^{(}$, Guifeng Jia ${ }^{\circ}$, Lifeng Cui* ${ }^{*}$, Jia Wang ${ }^{\circledR}$ \\ Department of Obstetrics and Gynecology, The First Hospital of Jilin University, Changchun, China \\ Email: *cuilifydyy@163.com
}

How to cite this paper: Lin, X., Shah, N.K., Jia, G.F., Cui, L.F. and Wang, J. (2021) Strumal Carcinoid of the Ovary: A Report of Two Cases. Open Journal of Obstetrics and Gynecology, 11, 1351-1360. https://doi.org/10.4236/ojog.2021.1110126

Received: September 24, 2021

Accepted: October 17, 2021

Published: October 20, 2021

Copyright $\odot 2021$ by author(s) and Scientific Research Publishing Inc. This work is licensed under the Creative Commons Attribution International License (CC BY 4.0).

http://creativecommons.org/licenses/by/4.0/ (c) (i) Open Access

\begin{abstract}
We describe two cases of strumal carcinoid of ovary, which is an extremely rare ovarian germ cell tumor composed of an intimate mixture of thyroid and carcinoid tissues. The first case involved a 63-year-old woman, who presented with a 1-month history of abdominal distension and unintentional weight loss $(5 \mathrm{~kg})$. Abdominal and chest computed tomography revealed right ovarian tumor and bilateral pleural effusion. Her thyroid-stimulating hormone level was slightly lower $0.475 \mu \mathrm{IU} / \mathrm{mL}$ (normal range: $0.55-4.78 \mu \mathrm{IU} / \mathrm{mL}$ ); however, the levels of FT3 and FT4 were normal. Intraoperatively, the right ovary was enlarged $(8.0 \mathrm{~cm} \times 7.0 \mathrm{~cm})$, with a smooth surface and intact capsule. Bilateral salpingo-oophorectomy with a total abdominal hysterectomy and an appendectomy was performed. The second case was a 54-year-old woman, in whom pelvic mass was recognized 2 months before. Intraoperatively, the left ovary was dumbbell-shaped $(20.0 \mathrm{~cm} \times 9.0 \mathrm{~cm} \times 9.0 \mathrm{~cm})$ and connected to two masses $(9.0 \mathrm{~cm} \times 8.0 \mathrm{~cm}$ and $8.0 \mathrm{~cm} \times 7.0 \mathrm{~cm}$, respectively). Her thyroid function test was normal $(0.70 \mu \mathrm{IU} / \mathrm{mL})$. Total abdominal hysterectomy, partial omentectomy, and pelvic adhesion lysis were performed. In both patients, intraoperative frozen section suggested strumal carcinoid of the ovary (stage IA). Ovarian strumal carcinoid should be included in a differential diagnosis of adnexal masses. The prognosis is considered good.
\end{abstract}

\section{Keywords}

Ovarian Strumal Carcinoid, Germ Cell Tumors, Severe Constipation, Ovarian Tumor, Ovarian Goiter, Case Report

\section{Introduction}

Strumal carcinoid of the ovary is an extremely rare ovarian germ cell tumor, featuring an intimate mixture of thyroid and carcinoid tumoral tissues. When 
the thyroid tissue composition exceeds $50 \%$, it can be diagnosed as an ovarian goiter [1]. It is most commonly found in the fifth and sixth decades of life and accounts for $0.3 \%-1 \%$ of all ovarian tumors and $3 \%$ of mature teratomas [2] [3]. Herein, we report two interesting cases of patients with primary strumal carcinoid of the ovary who had been admitted to our hospital's gynecological department in 2018. We discuss the clinical and histopathological features, treatment, and prognosis of these cases to enhance the overall understanding of strumal carcinoid of ovary and its importance in differential diagnosis.

\section{Case 1}

\subsection{Case Profile}

A 63-year-old woman, who experienced natural menopause 12 years prior, was hospitalized in April 2018 due to abdominal distension and unintentional weight loss that had been ongoing for $1 \mathrm{mo}$

The patient had experienced weight loss of about $5 \mathrm{~kg}$ over the previous month. She denied history of nausea, vomiting, and loss of appetite. Her bladder movement was normal. The patient's past medical and surgical histories were insignificant. The patient had no significant personal or family history.

The patient's general condition was good, and her vital signs were stable as well. Gastrointestinal examination revealed a slightly distended abdomen, with no tenderness and no rebound tenderness nor muscle tension; however, there was positivity for shifting dullness. The workup showed a slightly lower thyroid-stimulating hormone level $0.475 \mu \mathrm{IU} / \mathrm{mL}$ (normal range: 0.55 - $4.78 \mu \mathrm{IU} / \mathrm{mL}$ ); however, the levels of FT3 and FT4 were normal. The levels of serum tumor markers were enhanced, including that of carbohydrate antigen-125 (CA-125), which was $768.10 \mathrm{U} / \mathrm{mL}$ (normal range: 0 - $35 \mathrm{U} / \mathrm{mL}$ ).

Chest computed tomography (CT) revealed bilateral pleural effusion (Meig's syndrome) but absolutely no respiratory symptoms. Gynecological sonography revealed a mixed echogenicity that was predominantly hypoechoic and an irregular, solid mass, measuring $8.8 \mathrm{~cm} \times 7.5 \mathrm{~cm}$, behind the uterus. A considerable amount of free fluid was observed in the pouch of Douglas, encompassing around $7 \mathrm{~cm}$ of space.

\subsection{Course}

Intraoperative exploration showed that the ascites were pale yellow, the uterine morphology was normal, and the right ovary was enlarged (by $\sim 8.0 \mathrm{~cm} \times 7.0$ $\mathrm{cm}$ ), with a smooth surface and intact capsule. Intraoperative frozen section evaluation suggested strumal carcinoid of the right ovary. Consequently, bilateral salpingo-oophorectomy with a total abdominal hysterectomy and an appendectomy was performed. The exfoliated cells of the ascites appeared as individual heteromorphic cells upon microscopic analysis.

Postoperative pathological analysis of paraffin-embedded sections confirmed strumal carcinoid of the right ovary, as evidenced by thyroid adenomatous changes 
and carcinoid tumor changes (Figures $1(\mathrm{~A})-(\mathrm{C})$ ). The predominant carcinoid tissue component was strumal, with some mucinous portions. Dilated mucinous glands of the intestines were also observed. Immunohistochemical staining of the right ovary showed positivity for CD56, cytokeratin (CK), CK20, CK7, CK19, chromogranin A, synaptophysin and galectin-3 (focal) but negativity for human bone marrow endothelium marker-1 (Figure $1(\mathrm{D})$ ). The proliferation activity measured by the Ki67 index was 2\%. These histopathology findings revealed the mass to be a strumal carcinoid, stage IA (according to the American Joint Committee on Cancer staging manual, $7^{\text {th }}$ edition; i.e. the AJCC 2010) of the right ovary, without surface involvement, with unilateral confinement, and negative for cytopathology of the fluid from the pouch of Douglas.

The patient's postoperative course was stable, and her first postoperative bowel movement occurred within $48 \mathrm{~h}$ of surgery. There was no necessity for adjuvant chemoradiotherapy. The patient was discharged on postoperative day 8 . At 1-year follow-up after the surgery, her CA-125 was normal $(6.9 \mathrm{U} / \mathrm{mL})$ and thyroid-stimulating hormone indicated only subclinical hyperthyroidism (by thyroid function test; $0.498 \mu \mathrm{IU} / \mathrm{mL}$ ). Thyroid medication was not prescribed. Her bilateral pleural effusion and mild thyroid disorders resolved spontaneously over time.

\subsection{Prognosis}

The patient's condition is good to date, signifying a good prognosis following

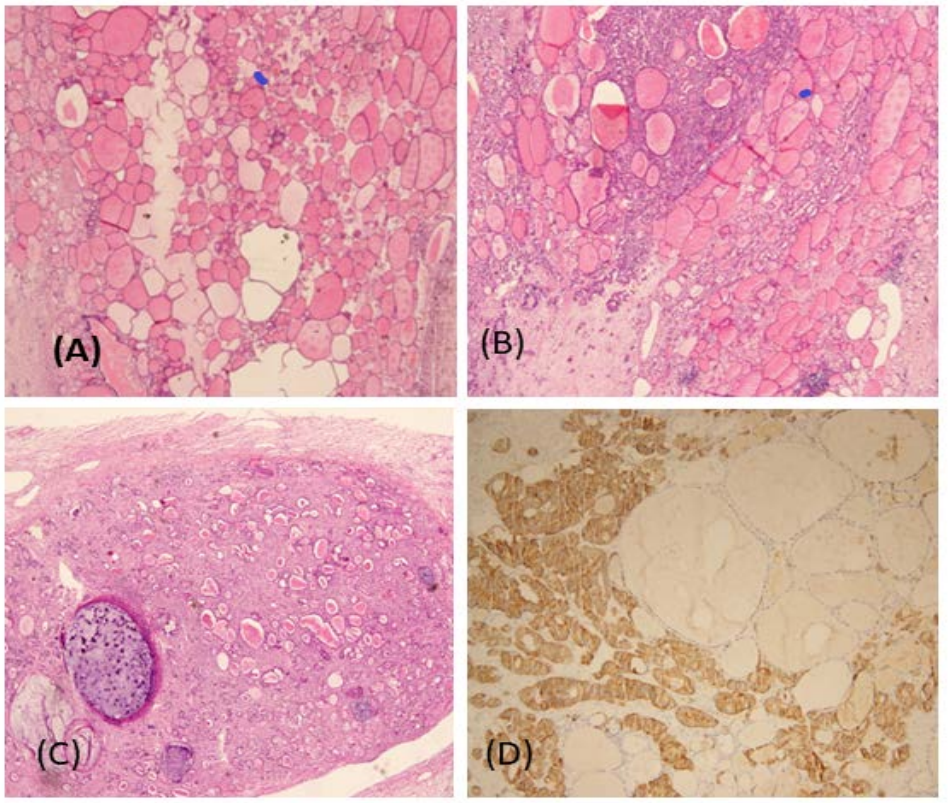

Figure 1. Histologic examination of the strumal carcinoid tumor of the ovary in Case 1. (A) Typical thyroid follicle in the pathological section of the ovary (hematoxylin-eosin (H\&E), 40x); (B) Typical carcinoid cells in the pathological section (H\&E, 40x); (C) Transitional areas of thyroid follicles and carcinoid cells in the pathological section (H\&E, 40×); (D) Immunohistologic staining of the strumal carcinoid tumor, showing positivity for synaptophysin $(100 \times)$. 
the surgical intervention.

\section{Case 2}

\subsection{Case Profile}

A 54-year-old woman, who had experienced natural menopause 3 years prior, was admitted to the gynecology department in September 2018 due to the presence of pelvic masses that had developed 2 mo previously.

The patient reported having no experience of abdominal pain nor vaginal bleeding during her post-menopausal period. The patient reported having normal diet, sleep pattern, and bladder habit; although, she had experienced severe constipation for the past 2 mo but with no significant change in her body weight. Being concerned, she went for color Doppler ultrasound examination in a hospital in Changchun city, which showed a pelvic mass, about $7 \mathrm{~cm}$ in diameter. Twenty-nine years previously, she had undergone bilateral tubal ligation. She had also undergone laparotomy for an ovarian cyst in a hospital in Changchun city 15 years prior, but the specific operative method and postoperative pathology were unknown. The patient had no significant personal and family history.

The patient's abdomen was soft and distended. Routine laboratory investigations, including tests for serum electrolytes and thyroid function $(0.70 \mu \mathrm{IU} / \mathrm{mL})$, were normal, but serum testing for tumor markers showed elevated CA-125 level (124 U/mL).

Gynecological ultrasound revealed an irregular, mixed heterogeneous echoic mass $(13.8 \mathrm{~cm} \times 7.9 \mathrm{~cm})$ having a predominant cystic component $(6.6 \mathrm{~cm} \times 5.9$ $\mathrm{cm})$ and some solid components $(1.6 \mathrm{~cm} \times 1.6 \mathrm{~cm})$, located in the left adnexal region behind the uterus. A moderate amount of fluid was present in the pouch of Douglas $(\sim 3.5 \mathrm{~cm})$.

\subsection{Course}

Exploratory laparotomy revealed yellow-colored ascites $(\sim 200 \mathrm{~mL})$ and the left ovary to be enlarged $(20.0 \mathrm{~cm} \times 9.0 \mathrm{~cm} \times 9.0 \mathrm{~cm})$ and dumbbell-shaped, in physical connection to two additional masses $(9.0 \mathrm{~cm} \times 8.0 \mathrm{~cm}$ and $8.0 \mathrm{~cm} \times 7.0$ $\mathrm{cm}$ respectively). The surface of the left ovary was smooth, multi-locular, and adhered to the left pelvic floor, with the left fallopian tube draping over it; the right fallopian tube and ovary were absent. Part of the mesentery and greater omentum were adhered to the right posterior wall of the uterus. There were no obvious abnormalities observed in the uterus. The left fallopian tube and ovary were excised and sent for detailed (postoperative) pathological examination. The intraoperative frozen section evaluation indicated strumal carcinoid of the ovary, with active foci of the thyroid follicles (Figure 2(A), Figure 2(B)). Based on these results, total abdominal hysterectomy, partial omentectomy, and pelvic adhesion lysis were performed.

Postoperative pathological examination of paraffin-embedded sections indicated ovarian goiter with carcinoid tissue, mainly composed of goiter characteristics and 

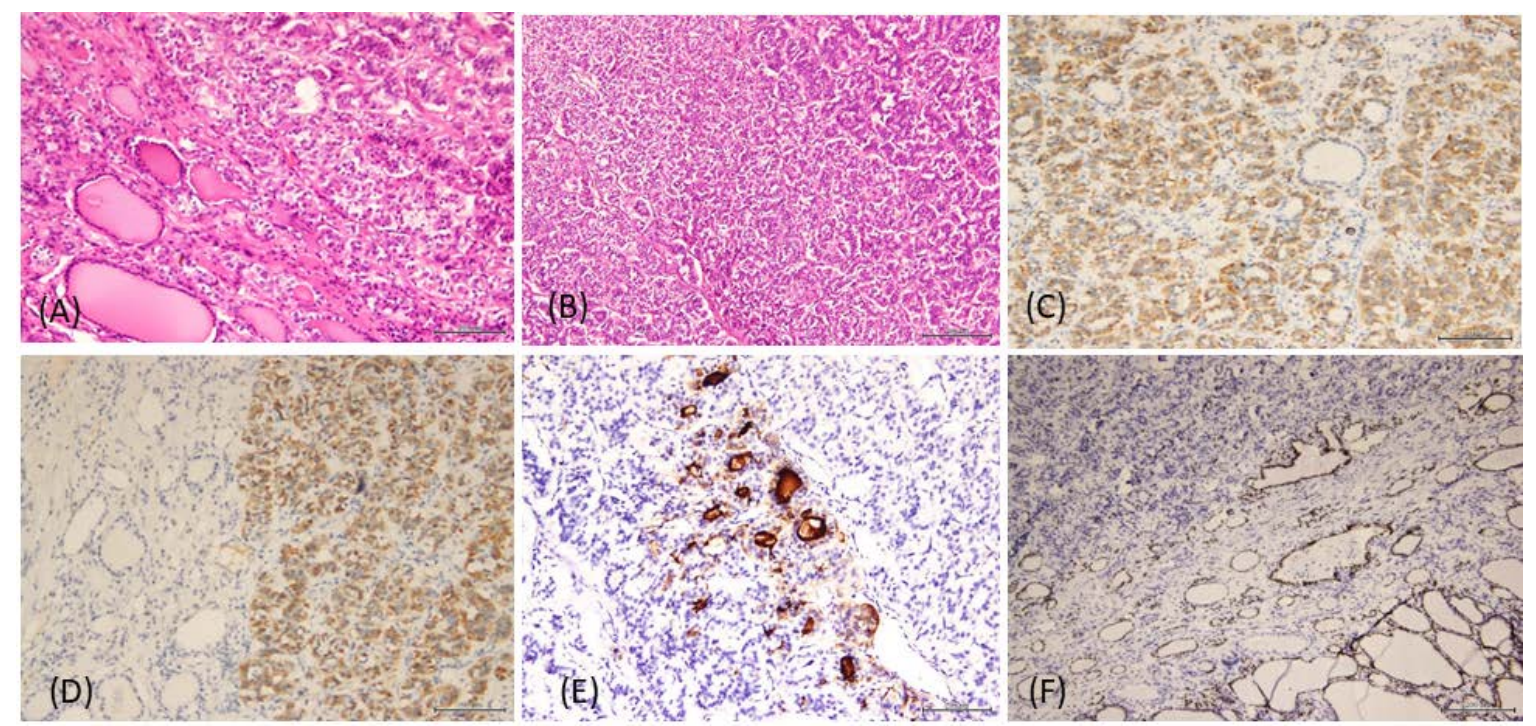

Figure 2. Histologic examination of the strumal carcinoid tumor of the ovary in Case 2. All sections are stained with hematoxylin-eosin. (A) Junction between the carcinoid and thyroid follicular tissues; (B) Characteristic view of the mixture of insular and trabecular carcinoids; (C)-(F) Immunohistochemical staining showed positivity for synaptophysin (C), chromogranin A (D), thyroglobulin (E), and thyroid transcription factor (F).

featuring cystic changes. Immunohistochemistry on the left ovary sections showed positivity for expression of CD56, CK, CK20, CK7, CK19, chromogranin A, synaptophysin, thyroid transcription factor 1, thyroglobulin, and galectin-3 (focal) (Figures 2(C)-(F)) but negativity for human bone marrow endothelium marker1. The proliferation activity measured by the Ki67 index was $2 \%$.

According to the Union for International Cancer Control (i.e. UICC) and AJCC $7^{\text {th }}$ edition, the tumor was stage IA, as there was no surface involvement and negative cytopathology for the fluid from the pouch of Douglas.

The patient recovered well in the postoperative period, without adjuvant chemoradiotherapy. Her first postoperative bowel movement occurred several hours after the surgery, and she was discharged on postoperative day 4 . Her constipation resolved dramatically, without further intervention. At 1-mo follow-up, results of the thyroid function test were within normal range $(0.58 \mu \mathrm{IU} / \mathrm{mL})$.

\subsection{Prognosis}

Since her 1-year follow-up, the patient has reported remaining well, passing stools every day without the use of laxatives. Therefore, we can say that the prognosis of the patient is good.

\section{Discussion}

\subsection{Tumor Pathology}

WHO classification describes strumal carcinoid of the ovary as a group of ovarian monodermal teratomas [4], which can be primary or metastatic. Robboy et al. [5] reported that generally, in metastatic diseases, the primary origin is the ileum; both ovaries can be affected, with the absence of a thyroid component. A 
previous case study suggested a four-fold decrease in the frequency of metastases of carcinoid cells from the gastrointestinal tract to ovaries, as compared to primary ovarian carcinoid cells [6]. Primary ovarian carcinoid tumors are extremely rare, representing less than $0.1 \%$ of ovarian malignancies [7], and they are endodermal in origin. The primary ovarian carcinoids are histologically divided into four major (pure) types: insular; trabecular; strumal; and, mucinous. A mixed type, which is composed of any combination of the pure types, has been reported as well [8].

Most cases of strumal carcinoid occur as a unilateral mass; nevertheless, one case report of a patient with strumal carcinoid in bilateral ovaries exists in the public literature [9]. Some researchers have found an association between primary ovarian carcinoids and mature cystic teratomas or mucinous tumors, which ultimately complicates preoperative diagnosis and increases the likelihood of missed diagnosis or misdiagnosis [10]. Therefore, a multidisciplinary approach, involving a surgeon, radiologist and pathologist, is required to accurately diagnose strumal carcinoid; immunohistochemical staining is necessary for confirmation and predicting prognosis of the ovarian carcinoid [11].

The thyroid component of strumal carcinoid exhibits positive expression for thyroxine, thyroid transcription factor 1, thyroglobulin and, rarely, calcitonin [12]. In contrast, the neuroendocrine component of strumal carcinoid exhibits positive expression for chromogranin A, somatostatin, serotonin, galectin-3, neuronspecific enolase, synaptophysin, and so on [13].

\subsection{Clinical Characteristics and Diagnosis}

Strumal carcinoid of the ovary most frequently presents in peri- or postmenopausal women, manifesting in vague and non-specific chief complaints [14]. Most patients initially attend the hospital to address development of a lower abdominal mass or are incidentally detected on routine check-up, by standard imaging. However, the strumal carcinoid has no specific features on imaging modalities (ultrasonography, CT, and magnetic resonance imaging). Hence, the preoperative diagnosis of strumal carcinoid seems nearly impossible, with our current technologies. An increased serum concentration of CA-125 is noted in most cases and may prompt suspicion of the potential diagnosis. However, apart from ovarian cancer, elevated CA-125 is seen in many malignant and benign conditions, such as pregnancy, liver diseases, cardiovascular diseases, and so on; therefore, its utility for ovarian malignancy is negated by low sensitivity and specificity. The gradual growth of strumal carcinoids may cause a slow but persistent abdominal distention; eventually, when the tumor reaches a significant size, the abdominal distension may be accompanied by discomfort or pain, as was present in our two cases.

Moreover, several cases of strumal carcinoid with refractory constipation have also been reported. In 1992, Motoyama et al. [15] were the first to report a case of severe constipation accompanying primary ovarian carcinoid; moreover, they illustrated how the constipation was caused by the overproduction of an inhibi- 
tory protein, peptide YY (PYY), by the tumor cells and not by the pressure effects of the tumor itself. Strumal carcinoids have foregut and hindgut origin, making them capable of secreting PYY [10] [15] [16]. PYY is normally secreted by the neuroendocrine cells in the gastrointestinal tract's mucosa, mainly by that in the colon, pancreas, and ileum. It has a physiologically inhibitory function on the gastrointestinal system, affecting such crucial functions as gastric acid secretion, pancreatic exocrine hormone secretion, gastric emptying, pancreatic insulin secretion, chloride secretion of small intestine and colon, jejunal and colonic motilities, etc. [16] [17] [18] [19] [20]. Therefore, it is postulated that at least $50 \%$ of PYY expression among the entire tumor cellular tissue would be the threshold to experiencing constipation [21].

As we have seen in our second case, the patient becomes relieved of severe constipation after complete surgical removal of the tumor. Indeed, Shigeta et al. [22] and Kawano et al. [23] both reported that patients with strumal carcinoids show dramatic improvement of constipation after surgery. Thus, serum level of PYY can be considered as an important tumor marker in patients with refractory constipation, as its level decreases after tumor resection.

It has also been documented that a minority $(\sim 8 \%)$ of patients with strumal carcinoids manifest clinical signs and symptoms of dysregulated steroid hormone production, such as endometrial hyperplasia, hirsutism, etc. Another $8 \%$ of cases present with hyperthyroidism, due to functioning thyroid tissue in the tumor cells [5]. Moreover, 1 case of strumal carcinoid with endocrine dysfunction manifesting as hyperinsulinemia, hypoglycemia, and pigmentation had also been reported [24]. In our first case, the patient presented with subclinical hyperthyroidism, which resolved spontaneously after the surgical treatment.

\subsection{Treatment and Prognosis}

Primary strumal carcinoid of the ovary is often unilateral, slow-growing, has low malignant potential, mostly having benign behavior if confined to one ovary, has less chance of recurrence, and is usually discovered in stage I; therefore, the tumor has an overall good prognosis. Surgery is an imperative step in patient management, as it allows for definitive diagnosis, surgical staging, and treatment planning. In young patients and patients who wish to preserve their fertility, partial adnexectomy is recommended (and has a favorable prognosis) when the patient also has a tumor confined to the ovary with intact capsule, normal contralateral adnexa and uterus, and absence of metastatic lesion. Moreover, Khadilkar et al. [25] reported a good prognosis in a 44-year-old-patient with strumal carcinoid of the ovary who also presented with contralateral ovarian, myometrium and lung metastases. However, total abdominal hysterectomy with bilateral salpingo-oophorectomy is recommended for patients whose family is completed and/or who present with invasive tumors; adjuvant chemotherapy is advisable in the case of distant metastasis. In the presence of metastatic thyroid elements, total thyroidectomy and 131I ablation are performed. Davis et al. [8] reported a 100\% 
survival rate in patients with stage I goiter carcinoid persisting for 5 - 10 years, whereas a 33\% 5-year survival rate was found for patients diagnosed at an advanced stage. Furthermore, Robboy et al. [5] reported the death of 1 patient out of 50 with ovarian strumal carcinoid tumor, due to recurrence at 18 mo after the surgical treatment.

In our 2 cases, the patients were of elderly age, with their families completed, and the tumors were unilateral with no metastasis; as such, total abdominal hysterectomy with bilateral salpingo-oophorectomy was performed, without any adjuvant chemoradiotherapy. We conducted follow-up examinations at the intervals of $1 \mathrm{mo}, 3 \mathrm{mo}, 6 \mathrm{mo}$, and 1 year postoperative for both. The prognosis appears to be favorable, and we are expecting no recurrences in the future.

\section{Conclusion}

Ovarian strumal carcinoid should be included in the differential diagnosis of adnexal lesions, if a woman is around $40-60$ years of age and presents with a chief complaint of pelvic mass associated with chronic progressive constipation. The gold-standard method for the diagnosis of strumal carcinoid involves pathological and immunohistochemical examinations. Future research is required to incorporate serum PYY as a tumor marker in the diagnosis and monitoring of the course of the tumor. Surgery is the mainstay treatment, and it has ranged from partial adnexectomy to more invasive surgeries followed by chemoradiotherapy, depending on the tumor stage. Overall, this tumor has a favorable prognosis, with an excellent survival rate.

\section{Acknowledgements}

The authors would like to thank Dr. Lifeng Cui for her expert advice and encouragement throughout this study.

\section{Informed Consent Statement}

Informed written consent was obtained from the patients for publication of this report and any accompanying images.

\section{CARE Checklist (2016) Statement}

The authors have read the CARE Checklist (2016), and the manuscript was prepared and revised according to the CARE Checklist (2016).

\section{Author Contributions}

Lin X, Shah NK and Cui L conceptualized the study; Lin X, Jia G, Wang J and Shah NK curated the data and provided software analysis; Shah NK, Lin X and Wang J performed the formal analysis and project administration; Cui L, Shah NK, Lin X and Jia G performed the investigation; Cui L, Lin X, Jia G, Wang J and Shah NK provided resources; Cui L, Lin X and Wang J provided validation; Lin X, Shah NK, Jia G, Wang J and Cui L wrote, reviewed and edited the manuscript. 


\section{Conflicts of Interest}

The authors declare no conflicts of interest regarding the publication of this paper.

\section{References}

[1] Roth, L.M. and Talerman, A. (2007) The Enigma of Struma Ovarii. Pathology, 39, 139-146. https://doi.org/10.1080/00313020601123979

[2] Noh, H.K., Kwon, B.S., Kim, Y.H., Lee, N.K., Choi, K.U., Suh, D.S., et al. (2017) Peptide YY Producing Strumal Carcinoid Tumor of the Ovary in a Postmenopausal Woman: A Rare Cause of Chronic Constipation. Obstetrics \& Gynecology Science, 60, 602-607. https://doi.org/10.5468/ogs.2017.60.6.602

[3] Antovska, V.S., Trajanova, M., Krstevska, I., Gosheva, I., Chelebieva, J. and Prodanova, I. (2018) Ovarian Strumal Carcinoid Tumour: Case Report. Open Access Macedonian Journal of Medical Sciences, 6, 540-543.

[4] Târcoveanu, E., Vasilescu, A., Fotea, V., Ciobanu, D., Crumpei, F. and Bradea, C. (2015) Rare Tumors, Rare Association: Ovarian Strumal Carcinoid-Retroperitoneal Cystic Lymphangioma. Chirurgia, 110, 294-299.

[5] Robboy, S.J. and Robert, E. (1980) Strumal Carcinoid of the Ovary: An Analysis of 50 Cases of a Distinctive Tumor Composed of Thyroid Tissue and Carcinoid. Cancer, 46, 2019-2034. https://doi.org/10.1002/1097-0142(19801101)46:9\%3C2019::AID-CNCR2820460921 \%3E3.0.CO;2-W

[6] Leniček, T., Davor, T., Soljačić-Vraneš, H., Kraljević, Z., Klarić, P., Kos, M., et al. (2012) Strumal Carcinoid of the Ovary: Report of Two Cases. Acta Clinica Croatica, 51, 649-653.

[7] Wu, L., Wang, Z., Dai, S., Zheng, J. and Li, J. (2016) Primary Strumal Carcinoid of the Ovary: A Case Report and Literature Review. International Journal of Clinical and Experimental Pathology, 9, 2409-2413.

[8] Davis, K.P., Hartmann, L.K., Keeney, G.L. and Shapiro, H. (1996) Primary Ovarian Carcinoid Tumors. Gynecologic Oncology, 61, 259-265.

https://doi.org/10.1006/gyno.1996.0136

[9] Zahradka, W. and Schulz, G. (1990) Bilateral Strumal Ovarian Carcinoid. Zentralblatt für Gynäkologie, 112, 171-174.

http://ovidsp.ovid.com/ovidweb.cgi? $\mathrm{T}=\mathrm{JS} \& \mathrm{PAGE}=$ reference $\& \mathrm{D}=\operatorname{med} 3 \& \mathrm{NEWS}=\mathrm{N}$ $\underline{\mathrm{AN}}=2336891$

[10] Talerman, A. and Vang, R. (2011) Blaustein's Pathology of the Female Genital Tract. In: Kurman, R.J., Ellenson, L.H., Ronnett, B.M., Eds., Germ Cell Tumors of the Ovary, 6th Edition, Springer, Boston, 847-907. https://doi.org/10.1007/978-1-4419-0489-8 16

[11] Ishida, M., Arimoto, T., Sandoh, K., Okano, K., Ebisu, Y., Ito, H., et al. (2019) Imprint Cytology of Strumal Carcinoid of the Ovary: A Case Report with Immunocytochemical Analysis. Diagnostic Cytopathology, 47, 218-221. https://doi.org/10.1002/dc.24042

[12] Lara, C., Cuenca, D., Salame, L., Padilla-Longoria, R. and Mercado, M. (2016) A Hormonally Active Malignant Struma Ovarii. Case Reports in Oncological Medicine, 2016, Article ID: 2643470. https://doi.org/10.1155/2016/2643470

[13] Kaćanski, M.M., Levakov, A., Dolai, M., Bozanić, S. and Amidzić, J. (2012) Morphology and Immunohistochemical Studies of Ovarian Strumal Carcinoid. Medi- 
cinski pregled, 65, 102-105. https://doi.org/10.2298/MPNS1204102M

[14] Salhi, H., Laamouri, B., Boujelbène, N., Hassouna, J.B., Dhiab, T., Hechiche, M., et al. (2017) Primary Ovarian Carcinoid Tumor: A Report of 4 Cases. International Surgery Journal, 4, 2826-2828. https://doi.org/10.18203/2349-2902.isj20173428

[15] Motoyama, T., Kafayama, Y., Watanabe, H., Okazaki, E. and Shibuya, H. (1992) Functioning Ovarian Carcinoids Induce Severe Constipation. Cancer, 70, 513-518. https://doi.org/10.1002/1097-0142(19920715)70:2\%3C513::AID-CNCR2820700223 \%3E3.0.CO;2-P

[16] Matsuda, K., Maehama, T. and Kanazawa, K. (2002) Strumal Carcinoid Tumor of the Ovary: A Case Exhibiting Severe Constipation Associated with PYY. Gynecologic Oncology, 87, 143-145. https://doi.org/10.1006/gyno.2002.6785

[17] Kachhawa, G., Kumar, S., Singh, G., Mathur, S., Kumar, L. and Sharma, J. (2011) Ovarian Strumal Carcinoid Presenting as Severe Progressive Constipation. Journal of Surgical Case Reports, 2011, 5. https://doi.org/10.1093/jscr/2011.8.5

[18] Sulaiman, S., Chia, Y.N. and Namuduri, R.V.D. (2013) Strumal Carcinoid Tumour of the Ovary Presenting with Severe Constipation. Singapore Medical Journal, 54, e21-e23. https://doi.org/10.11622/smedj.2013021

[19] Takatori, E., Shoji, T., Miura, J., Takeuchi, S., Yoshizaki, A. and Sugiyama, T. (2012) Case of Peptide-YY-Producing Strumal Carcinoid of the Ovary: A Case Report and Review. Journal of Obstetrics and Gynaecology Research, 38, 1266-1270. https://doi.org/10.1111/j.1447-0756.2012.01859.x

[20] Yamaguchi, M., Tashiro, H., Motohara, K., Ohba, T. and Katabuchi, H. (2013) Primary Strumal Carcinoid Tumor of the Ovary: A Pregnant Patient Exhibiting Severe Constipation and CEA Elevation. Gynecologic Oncology Case Reports, 4, 9-12. https://doi.org/10.1016/j.gynor.2012.11.003

[21] Muller, K.E., Tafe, L.J., Gonzalez, J.L., West, L.A. and Schned, A.R. (2015) Ovarian Strumal Carcinoid Producing Peptide YY Associated with Severe Constipation: A Case Report and Review of the Literature. International Journal of Gynecological Pathology, 34, 30-35. https://doi.org/10.1097/PGP.0000000000000117

[22] Shigeta, H., Taga, M., Kurogi, K., Kitamura, H., Motoyama, T. and Gorai, I. (1999) Ovarian Strumal Carcinoid with Severe Constipation: Immunohistochemical and mRNA Analyses of Peptide YY. Human Pathology, 30, 242-246. https://doi.org/10.1016/S0046-8177(99)90284-8

[23] Kawano, K., Ushijima, K., Fujimoto, T., Komai, K. and Kamura, T. (2007) Peptide YY Producing Strumal Carcinoid of the Ovary as the Cause of Severe Constipation with Contralateral Epithelial Ovarian Cancer. Journal of Obstetrics and Gynaecology Research, 33, 392-396. https://doi.org/10.1111/j.1447-0756.2007.00544.x

[24] Ashton, M.A. (1995) Strumal Carcinoid of the Ovary Associated with Hyperinsulinaemic Hypoglycaemia and Cutaneous Melanosis. Histopathology, 27, 463-467. https://doi.org/10.1111/j.1365-2559.1995.tb00311.x

[25] Khadilkar, U.N., Pai, R.R., Lahiri, R. and Kumar, P. (2000) Ovarian Strumal Carcinoid-Report of a Case That Matastasized. Indian Journal of Pathology \& Microbiology, 43, 459-461. 